\title{
DOSSIÊ: TRABALHO DOCENTE NO CONTEXTO DA INCLUSÃO ESCOLAR $^{1}$
}

\section{APRESENTAÇÃO}

O dossiê aqui reunido traz artigos que problematizam e discutem o trabalho docente como elemento fundamental no processo de ensino e aprendizagem escolar para a construção de uma escola de qualidade para todos. Enfatizando práticas pedagógicas com alunos público-alvo da Educação Especial - alunos com deficiências, transtorno global do desenvolvimento e altas habilidades/superdotação -, os trabalhos apresentam investigações desenvolvidas em todos os níveis de ensino, da Educação Infantil à Superior, relacionadas à formação de professores, ao trabalho docente e à reorganização escolar, bem como uma reflexão sobre a temática tendo como base o modelo espanhol de inclusão escolar.

São 13 artigos na forma de relato de pesquisa e ensaio teórico, em sua maioria vinculados a pesquisadores ligados ao Programa de Pós-Graduação em Educação Escolar da Faculdade de Ciências e Letras da Unesp de Araraquara, embora tenhamos contado com a colaboração de colegas vinculados a outras unidades da Unesp, à Universidade Federal de São Carlos e a Universidade Federal da Grande Dourados.

O artigo "O trabalho pedagógico para alunos público-alvo da Educação Especial: investigando a inclusão na educação infantil", de autoria de Tamiris Aparecida Fachinetti, Beatriz A. Barbosa do Nascimento e de Cláudia Regina Mosca Giroto, apresenta investigação sobre o fazer pedagógico na sala comum com alunos da educação especial na educação infantil. Para tanto, foram realizadas observações em salas de aula de quatro escolas de educação infantil onde foram observadas quatro professoras que tinham alunos com deficiência matriculados. Os resultados desse estudo mostram de que forma foi realizada a inclusão em sala e como as professoras utilizavam sua prática docente para atender a todos.

"Educação Inclusiva: um estudo de caso sobre o trabalho docente na educação infantil", escrito por Bruna Rafaela de Batista e por Luci Pastor Manzoli, traz dados de

1 Os dados aqui considerados encontram-se vinculados ao Projeto CNPq Processo no 406241/2016-3, ao qual as autoras se encontram vinculadas. 
pesquisa que também analisou como se dá o trabalho pedagógico com alunos PAEE em uma sala de aula comum na educação infantil. A coleta dos dados ocorreu em escola de cidade do interior do estado de São Paulo, através da aplicação de entrevista com roteiro semiestruturado de questões que abordou dados de identificação e quatro eixos temáticos: Informações sobre o aluno PAEE; Trabalho docente; Escola e Família; e Educação Inclusiva. Como resultado, constatou-se a realização de trabalho pedagógico voltado à inclusão da aluna com deficiência, assim como a necessidade de maior colaboração entre os profissionais da escola e maior participação por parte da família.

Denominado "Trabalho docente com alunos público-alvo da Educação Especial na educação infantil", o artigo de Jaqueline Belga Marques e de Cláudia Regina Mosca Giroto fecha o tema da educação infantil e mostra estudo que teve como principal objetivo trazer reflexões sobre o trabalho do professor com alunos PAEE em sala de aula comum. Foi realizada pesquisa de abordagem qualitativa com uma docente da educação infantil que atua em escola da rede municipal, no interior do estado de São Paulo. Foi possível perceber o trabalho pedagógico voltado à inclusão de aluno PAEE, assim como o trabalho em colaboração com escola, professora do AEE, família e demais profissionais que atendem a criança. Em contraponto, foi discutido que apesar da entrevistada afirmar que é a favor da inclusão escolar, contradiz-se a respeito da questão.

Sobre o ensino fundamental I, o artigo "A inclusão de alunos público alvo da Educação Especial no ensino fundamental I através do olhar dos professores", de autoria de Relma Urel Carbone Carneiro e de Flávia Uehara, analisa como tem se dado a inclusão escolar de alunos público-alvo da Educação Especial nas séries iniciais do Ensino Fundamental. Foi aplicado questionário a 13 professores de classe comum atuantes em escola municipal, no interior do estado de São Paulo, que tinham em suas turmas alunos com deficiência. Os resultados demonstraram que a matrícula na classe comum não significa inclusão na turma e que a concepção dos professores sobre a inclusão é, na maioria das vezes, negativa: professores não se percebem como agentes de mudanças necessárias, reivindicam formação, apoio estrutural, pedagógico e humano.

"Inclusão escolar de alunos público-alvo da Educação Especial: como se dá o trabalho pedagógico do professor no ensino fundamental I?" de Suzana Sirlene da Silva e Relma Urel Carbone Carneiro, relata pesquisa desenvolvida com professoras que 
trabalham em escolas comuns e que têm alunos com deficiência incluídos em sala de aula com o objetivo de verificar como está se dando o trabalho docente/pedagógico. Foi aplicado questionário livre, com questões abertas, a cinco professoras de escolas públicas e privadas. Os dados mostraram que as professoras trabalham a partir da naturalização do aluno com atividades adaptadas e diferenciadas, não consideram que haja trabalho colaborativo entre elas e professoras especialistas, mas concordam que a inserção do aluno público-alvo da educação especial traz ganhos no contexto geral, sendo que é o docente a peça importante para a real inclusão.

$\mathrm{O}$ artigo "O processo de inclusão de uma aluna deficiente intelectual em uma escola comum do ensino fundamental I" escrito por Camila Lourenço Morgado e Sílvio Henrique Fiscarelli, o último que trata das séries iniciais do ensino fundamental, analisa as concepções do professor acerca da profissão docente, da inclusão, do auxílio por parte da equipe gestora e do AEE, da concepção de aprendizagem do aluno com deficiência e do contato com a família. Muitos avanços foram alcançados no âmbito legal no que diz respeito a inclusão dos alunos com deficiência na escola comum, porém a realidade da sala de aula ainda é bastante precária, o que dificulta a inclusão efetiva.

Denominado "Educação Inclusiva: o trabalho pedagógico com alunos públicoalvo da Educação Especial no ensino fundamental II na sala de aula comum" o artigo de autoria de José Adnilton Oliveira Ferreira e Relma Urel Carbone Carneiro discute o trabalho pedagógico com alunos público-alvo da educação especial (PAEE) em sala de aula comum em escola da rede privada que atende alunos do ensino fundamental II. Foi aplicado questionário com perguntas abertas e fechadas a sete professores do ensino fundamental II e à coordenadora pedagógica da escola. O estudo traz contribuições teóricas e práticas significativas para o trabalho pedagógico no processo de inclusão escolar dos alunos (PAEE) em sala de aula comum no ensino fundamental II.

Também com o objetivo de analisar a inclusão escolar de alunos com deficiência no ensino fundamental II, Juliana Cavalcante de Andrade Louzada e Sandra Eli Sartoreto de Oliveira Martins apresentam o artigo " Educação inclusiva: o olhar do professor sobre a prática pedagógica para o aluno com deficiência no ensino fundamental II". A análise mostra que embora docentes recebam informações prévias sobre características do aluno PAEE que irão receber em sala de aula e a escola ofereça algum suporte, ainda há dificuldades no tocante a adaptação curricular. Além disso, dentro de uma mesma escola, alunos com diferentes deficiências são tratados de forma 
diferenciada pelos seus colegas de sala, o que prejudica o processo de inclusão na escola comum.

Com vistas a investigar a inclusão escolar no ensino médio, o artigo "Inclusão escolar no ensino médio: desafios da prática docente" de autoria de Patrícia Mara Almeida Garcia, Rosimeire Ferreira Diniz e Morgana de Fátima Agostini Martins apresenta dados de pesquisa realizada com professores do Ensino Médio, de escola do interior de Minas Gerais, que atua com alunos público-alvo da educação especial. Os dados foram coletados através de questionário aplicado a cinco professores, de observações com registro em diário de campo para caracterizar a escola em relação a sua estrutura física e para compreensão dos processos pedagógicos, de análise do Projeto Político Pedagógico e da dinâmica de estruturação da escola. Os resultados mostram que a inclusão de alunos PAEE no Ensino Médio ainda é muito frágil, que os professores não se sentem preparados e, portanto, não realizam adaptações considerando diferenças, que o PPP não é elaborado de forma coletiva ou participativa e que se faz necessário engajamento de toda equipe escolar na busca das alterações necessárias.

$\mathrm{O}$ artigo "Acessibilidade na educação superior também envolve o trabalho pedagógico" de Eliane Aparecida Piza Candido, Cláudia Regina Siena do Nascimento e Morgana de Fátima Agostini Martins apresenta estudo sobre inclusão na Educação Superior e práticas pedagógicas que podem contribuir para a realização dessa inclusão, salientando a dívida histórica que o Brasil possui baseada na exclusão e segregação de pessoas com deficiência que estão em constante luta por seus direitos, que aos poucos têm sido garantidos na Educação Básica e, atualmente, objetiva envolver de forma mais efetiva a Educação Superior. A partir de levantamento bibliográfico sobre o tema, bem como da verificação de documentos legais nacionais que explicitam compromissos políticos brasileiros na incessante luta pela conquista da inclusão educacional, as autoras observam a necessidade de desmantelar obstáculos, combater preconceito e medidas excludentes que dificultam acesso e permanência de pessoas com deficiência nessa modalidade de ensino.

O artigo "Formação em serviço de professores comuns e especializados e suas implicações na prática: uma experiência de consultoria colaborativa" de autoria de Patrícia Moralis Caramori apresenta parte de resultados de pesquisa de abordagem qualitativa fundamentada na perspectiva participativa e interpretativa, que objetivou oferecer formação continuada em serviço a professores regulares e de educação 
especial, sob o enfoque de consultoria colaborativa, tendo como base teórica os critérios de Experiência de Aprendizagem Mediada de Reuven Feuerstein. Por meio de filmagem, observação e reuniões reflexivas com participação de duas professoras do ensino comum e uma professora de educação especial, os resultados apontam para a importância do critério de mediação, de significado, bem como, da consultoria colaborativa como caminho eficaz para formação em serviço com vistas a uma escola inclusiva.

O interesse pela temática de formação de professores para inclusão escolar foi a tônica do artigo "Formação de professores para alunos público alvo da Educação Especial: algumas considerações sobre limites e perspectivas" escrito por Aline Picoli Otalara e Maria Júlia Canazza Dall'Acqua, o qual discute o tema a partir de análise das políticas, das leis e da produção na área.

Finalizando o dossiê, temos o artigo de Maria Odete de Mattos e de José Luís Bizelli intitulado "Atendimento educacional para alunos com necessidades educativas especiais na Espanha". Os autores apresentam - a partir de observação direta e de análise documental - a organização do atendimento educacional para alunos com necessidades educativas especiais na Espanha, país que tem sido apontado com referência na organização da escola inclusiva e nos modelos organizativos para seu atendimento. Depois de breve explicação sobre o sistema educacional espanhol e de análise sobre o desenho jurídico-institucional vigente, são apresentados os recursos humanos disponibilizados, as funções dos mesmos no sistema e como escolas se organizam para desenvolver o atendimento a alunos com deficiência incluídos na escola comum.

A reunião dos artigos neste dossiê se apresenta como possibilidade de reflexão para estudiosos da Educação que se preocupam com a qualidade do serviço oferecido pela escola, especialmente em momento de mudança de paradigma como o que estamos atravessando, momento em que acolhimento e valorização de todos independentemente de quaisquer especificidades - é imperativo. Pensar o trabalho docente no contexto delimitado - considerando todos os níveis de ensino, da educação básica à superior - tem um sentido de urgência.

Parabenizo os autores pelos artigos apresentados, certa de que há contribuições para as reflexões sobre a Educação Inclusiva e para a prática pedagógica cotidiana.

Desejo a todos uma ótima leitura. 
Dossiê: Trabalho Docente no Contexto da Inclusão Escolar Relma Urel Carbone Carneiro (Org.)

Relma Urel Carbone Carneiro

(Organizadora)

RIAEE - Revista Ibero-Americana de Estudos em Educação, v. 11, n. esp. 2, p.856-861, 2016. E-ISSN: $1982-5587$ DOI: https://dx.doi.org/10.21723/riaee.v11.esp2.p856-860 